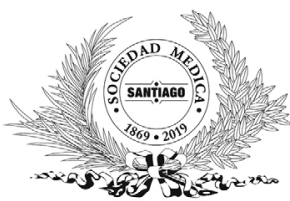

\section{Sociedad Médica de Santiago Sociedad Chilena de Medicina Interna 150 años al Servicio de la Medicina}

\author{
GILBERTO GONZÁLEZ V. ${ }^{1}$
}

\author{
Medical Society of Santiago \\ (Chilean Society of Internal Medicine) \\ 150 years to the Service of Medicine
}

'Presidente Sociedad Médica de Santiago (Sociedad Chilena de Medicina Interna). Santiago, Chile.
1 1 próximo 02 de septiembre, la Sociedad Médica de Santiago celebrará el aniversario 150 de su fundación en 1869. Un siglo y medio de existencia es por cierto un período extenso de tiempo. En escala humana, 150 años es algo muy superior a la expectativa actual de vida de cualquiera y según algunos, 150 años representa la vida productiva de hasta seis generaciones sucesivas. Tal antigüedad, también es un período relevante de tiempo al compararlo con la existencia de otras instituciones similares, ya sea nacionales o extranjeras. De hecho, la Sociedad Médica de Santiago, es la sociedad médica más antigua de Chile, constituye el centro y origen de la mayoría de las organizaciones y sociedades médicas del país y se cuenta también entre las más antiguas a nivel global. Luego, cumplir 150 años es razón suficiente per se para festejar, pero en este caso lo es también, porque la Sociedad Médica de Santiago alcanza sus 150 años de vida con una trayectoria ininterrumpida y fiel a su espíritu fundacional. Promover la educación médica continua de sus socios, aportar en la difusión del conocimiento y colaborar en todas las tareas necesarias para mejorar la salud de la población en Chile, ha sido siempre la misión de la Sociedad Médica de Santiago. En otras palabras y como menciona el logo conmemorativo de este aniversario, son 150 años al servicio de la medicina.

La Sociedad Médica de Santiago se originó a mediados del siglo XIX por iniciativa de un pequeño grupo de visionarios alumnos de medicina, que deseaban compartir conocimientos, actualizarlos, estimular la investigación y discutir las noticias que, en esa época, llegaban desde Europa. Esta idea fue respaldada rápidamente y hecha suya también por sus profesores, siendo electo el Dr. José Joaquín Aguirre, entonces decano de la Facultad de Medi- cina de la Universidad de Chile, como el primer presidente de la Sociedad Médica de Santiago. En una época en que el acceso al saber era privilegio de unos pocos, surge esta asociación entre alumnos y profesores para enriquecer el conocimiento de muchos. Esta idea fuerza, búsqueda de la verdad médica y sin otra tutela que la academia, ha sido y es la esencia de la Sociedad Médica de Santiago. De ella se originaron las pioneras reuniones clínicas que acontecieron todos los viernes de 20 a $22 \mathrm{~h}$ en la sede de la Sociedad Médica durante sus primeros 100 años de vida, sus numerosos cursos y congresos que hasta la fecha han complementado y enriquecido la formación académica de decenas de miles de médicos nacionales y extranjeros y por supuesto también, la edición de la Revista Médica de Chile, la revista de mayor antigüedad y una de las más importantes en su área entre los países de habla hispana. Sin embargo, el actuar de la Sociedad Médica de Santiago no se ha limitado a solo promover el saber de sus socios, para beneficio de unos pocos. Muy por el contrario, el sello de su trabajo ha sido cultivar el conocimiento médico, pero procurando siempre servir y aportar en el bienestar de la salud de toda nuestra población. Ejemplo de esto fue la participación de muchos de sus socios en la asistencia médica durante la Guerra del Pacífico, lo cual implicó la pérdida de varios de ellos en dicho conflicto. El primero de tales mártires fue el cirujano Pedro Videla de la Covadonga, cuya memoria honra hasta el día de hoy un buque de la armada chilena que llevando su nombre, cumple labores de asistencia sanitaria en lugares remotos del sur del país. La Sociedad Médica participó también desde su gestación y con gran protagonismo durante todo el siglo XX en la lucha contra las enfermedades infecto-contagiosas que azotaron tal época. Hoy, esa lucha continúa con el mismo compromiso de 
ayer, pero enfrentando ahora nuevas enfermedades, como las del sistema circulatorio, cáncer y otras que constituyen las causas principales de enfermedad o muerte en nuestro país. En todo este período y como parte de su legado, la Sociedad Médica de Santiago ha apoyado y colaborado activamente en la creación de importantes políticas y organismos públicos de salud, como la Ley de Medicina Preventiva, el antiguo Servicio Nacional de Salud, el Colegio Médico de Chile, la Corporación Nacional Autónoma de Certificación de Especialidades Médicas (CONACEM), la Asociación de Sociedades Científicas Médicas de Chile (ASOCIMED) o la Agencia Acreditadora de Programas y Centros Formadores de Especialistas Médicos (APICE), todas éstas, iniciativas o instituciones que actuando desde distintos ámbitos de la profesión médica sirven al propósito común de una mejor medicina y bienestar de la salud en Chile. Junto a estas iniciativas, debe mencionarse además, la fructífera labor de vinculación de la Sociedad Médica con instituciones del extranjero, destacando entre éstas su relación con el American College of Physicians, cuyo primer capítulo en Sudamérica fue creado en Chile en 1983, su membresía como socio fundador en 1998 de la Sociedad Latinoamericana de Medicina Interna y su rol en la International Society of Internal Medicine, que alcanzara un momento muy distinguido para nuestra Sociedad y el país, el año 2012 cuando Chile fue la sede del XXXI Congreso Mundial de Medicina Interna. Además, desde el 2010, el editor jefe de la Revista Médica de Chile integra, como único representante de revista en habla hispana, el prestigioso International Committee of Medical Journal Editors, institución independiente que lidera mundialmente las recomendaciones para la comunicación de la investigación biomédica.

En la actualidad, aproximándose a sus 150 años de vida, la Sociedad Médica de Santiago, continúa su labor, procurando mantenerse fiel a sus principios fundadores, su noble tradición y su orgullosa historia. Cuenta para ello con más de 1.000 socios presentes en todo el país, el apoyo sostenido de sus sociedades filiales y sucesivos directorios, además de un notable personal de colaboración. Todos ellos desarrollan una reconocida labor en la educación médica continua, donde ahora y acorde a los tiempos, el auditorio ha sido reemplazado mayoritariamente por la trasmisión digital a distancia como vía de aprendizaje, el papel sustituido por la edición electrónica en la Revista Médica de Chile y el Congreso Anual de Medicina, espacio muy esperado principalmente por generaciones de jóvenes médicos, se alimenta con la presentación electrónica de trabajos y aplicaciones para teléfonos inteligentes, instrumentos todos que han reemplazado el antiguo póster o voluminoso libro de resúmenes en papel. Sin embargo, en todas estas actividades se mantiene el mismo espíritu de excelencia y pasión en sus asistentes y docentes al igual que otrora, muchos de nosotros viviéramos en nuestra época de estudiante, interno o residente.

$\mathrm{Al}$ iniciar este año en que la Sociedad Médica de Santiago cumple 150 años de vida, esta breve reseña de su trayectoria y logros fundamenta el ánimo con que su directorio aspira conmemorar tal aniversario, celebrar este importante hito en conjunto con toda la comunidad médica nacional. Entiende de esta forma que la Sociedad Médica de Santiago, al igual que otras instituciones significativas de la República, es patrimonio del país y no solo de sus socios. Luego, el sello que espera darle a tales actividades conmemorativas, será el poder contar con la amplia participación no solo de muchos de nuestros colegas, socios o filiales, sino también con la de otras organizaciones médicas, autoridades del país e invitados extranjeros. Entre otras iniciativas de celebración, se ha decidido adelantar la fecha habitual de nuestro congreso anual, el cual se realizará este año entre el 02 al 04 de septiembre, coincidiendo de esta forma con la fecha de aniversario de los 150 años de la Sociedad. Además, se ha dispuesto que este congreso cuente con un programa especial elaborado en conjunto con nuestras sociedades filiales, en el marco de una amplia revisión y discusión de los temas relevantes de la medicina de hoy y del mañana. Los invito desde ya a colaborar y participar en todas estas actividades, cuyo detalle será anunciado oportunamente.

El referente principal de estas líneas ha sido el destacado y hermoso libro del Dr. Camilo Larraín: "La Sociedad Médica de Santiago y el Desarrollo Histórico de la Medicina en Chile". De éste, al finalizar, deseo citar las palabras que dijera con ocasión de la celebración del cincuentenario de la Sociedad Médica de Santiago, su entonces Vicepresidente el Dr. Luis Vargas Salcedo y que hoy, 100 años después, mantienen plena vigencia e importa tener presente al conmemorar los 150 años de la Sociedad Médica de Santiago : "Nuestra Sociedad ha vivido alejada de todo momento mezquino; las brisas políticas jamás han llegado a nuestra casa y podemos proclamar con orgullo que su tribuna ha sido siempre libre para todo asunto de biología y medicina. Solo la ciencia y los problemas sanitarios han agitado el ambiente sereno de mutuo respeto con que se caracterizan sus sesiones científicas. Ninguno de los grandes problemas sanitarios de nuestro país ni los grandes descubrimientos de la ciencia han dejado de animar y provocar conferencias o amplias discusiones aclaratorias". 